Research article

\title{
The first management of a marine invader in Africa: The importance of trials prior to setting long-term management goals
}

\author{
Clova A. Mabin $^{\mathrm{a}}$, John R.U. Wilson ${ }^{\mathrm{a}, \mathrm{b}}$, Johannes J. Le Roux ${ }^{\mathrm{a}, \mathrm{c}}$, Prideel Majiedt ${ }^{\mathrm{b}}$, Tamara \\ B. Robinson ${ }^{a, *}$
}

${ }^{a}$ Centre for Invasion Biology, Department of Botany and Zoology, Stellenbosch University, Matieland, 7602, South Africa

${ }^{\mathrm{b}}$ South African National Biodiversity Institute, Kirstenbosch Research Centre, Cape Town, South Africa

${ }^{\mathrm{c}}$ Department of Biological Sciences, Macquarie University, Sydney, New South Wales, 2109, Australia

\section{A R T I C L E I N F O}

\section{Keywords:}

Carcinus maenas

Invasive species

Marine crab

South Africa

Trial management

\begin{abstract}
A B S T R A C T
Biological invasions severely impact on marine ecosystems around the world, but to date management is rare and has not previously been attempted in Africa. This study documents a trial management programme aimed at informing a national management strategy for the invasive European shore crab, Carcinus maenas, in South Africa. The approach involved testing control methods used elsewhere (baited traps, crab condos, diver collections and sediment dredging) and adapting these to the local context. Following these trials, baited traps were deployed over the course of the year, and the catch per unit effort (CPUE) tracked. A total of 36,244 crabs were collected during the management period, six times more than a pre-management population estimate. The population was not extirpated and CPUE increased once trapping ceased. The cost of attempting nationwide eradication is prohibitive, particularly given the lack of current impacts by this crab in this region and the possibility of reintroduction. We highlight key administrative challenges encountered, and the importance of such pilot trials in setting long-term goals when attempting alien species management interventions.
\end{abstract}

\section{Introduction}

Biological invasions have caused notable impacts in marine systems (reviewed in Ojaveer et al., 2018). In situations where the impacts associated with an invasive species are severe (Frazer et al., 2012), or the species is known to be problematic elsewhere (Anderson, 2005), management might be deemed necessary. However, attempting such management is only worthwhile if it is likely to be effective. The potential effectiveness of management can be assessed in terms of administrative and scientific feasibility (for a discussion specifically on eradication feasibility, see Panetta, 2009). Administrative feasibility considers the logistics of management (e.g. programme duration, funding, permitting and personnel). In contrast, the extent of the invasion, the biology of the target species and the availability of appropriate control methods determine scientific feasibility. Assessing scientific feasibility is often the initial step of management programmes, in particular, this involves determining the susceptibility of the target species to control techniques (Panetta, 2015). This can be determined using previous experience or through field trials undertaken in the local context. But prior to the initiation of a long-term or large-scale eradication programme, there should ideally also be some estimation of the administrative feasibility. Unfortunately, such estimations are rarely included in scientific literature and data on socio-economic factors are often not available (Pluess et al., 2012), though see Panetta et al. (2011) and references in Wilson et al. (2017) for examples for plant eradications. We explore these ideas for invasive European shore crab (Carcinus maenas) management in South Africa.

South Africa has a long history of ecological and socio-economic impacts due to biological invasions (van Wilgen and Wilson, 2018), and several species have been targeted for eradication (Wilson et al., 2013). However, there has been no attempted management of a marine invasive species either in South Africa or, as far as we are aware, elsewhere in Africa. As part of efforts to expand the management of biological invasions to marine settings, funding was provided by the then South African Department of Environmental Affairs through the South African National Biodiversity Institute to initiate management efforts on marine invaders. As C. maenas had a restricted distribution (Mabin et al., 2017), but was known to have impacts in several invaded regions

\footnotetext{
* Corresponding author.

E-mail address: trobins@sun.ac.za (T.B. Robinson).
} 
globally (Grosholz et al., 2000; Matheson et al., 2016), this species was chosen as the management target.

Various management methodologies for C. maenas have been explored (Thresher, 1997), including biological (Murphy and Goggin, 2000), chemical (Hanks, 1961), and physical control (Duncombe and Therriault, 2017). However, the preferred method of control, especially in relatively enclosed areas such as bays or harbours, is via traps containing non-poisonous bait (Turner et al., 2016; Duncombe and Therriault, 2017). The success of different management options can be context dependent (Shea et al., 2005), and often the most appropriate management approaches require a combination of several different techniques (Courchamp and Sugihara, 1999). Moreover, as population structure, demographics and distribution of invasive species should change as management progresses, the efficacy of different control options might also change (Taylor and Hastings, 2004; Chades et al., 2011).

The aims of this study were firstly to identify the best management practices for C. maenas in South Africa and secondly, to undertake a pilot management programme on a small localised population so that the scientific and administrative feasibility of eradicating the species from South Africa could be estimated.

\section{Methods}

\subsection{Target species}

Carcinus maenas is a member of the Portunid family which is native to Europe but has a global distribution (Carlton and Cohen, 2003). The marine crab has a pelagic larval stage which lasts approximately 40 days (Williams, 1967) before the larvae return to inshore waters to settle as megalopae (Behrens Yamada, 2001). The megalopae then develop into juvenile crabs which can reproduce once a minimum carapace width of $27 \mathrm{~mm}$ is obtained (Mohamedeen and Hartnoll, 1989). A female crab is capable of producing two clutches per annum, with a maximum of 185 , 000 eggs per clutch (Broekhuysen, 1936), indicating this species' potential for rapid population growth.

\subsection{Location}

Carcinus maenas was first detected in South Africa in 1983 (Joska and Branch, 1986), but is largely confined to the Table Bay and Hout Bay harbours with intertidal populations having declined through time (Mabin et al., 2017). Table Bay receives large volumes of international shipping traffic, including commercial ships, fishing vessels and yachts. This harbour supports the largest and most dense population of C. maenas in the country (Robinson, unpublished data 2013). Hout Bay harbour is a smaller semi-enclosed harbour, $30 \mathrm{~km}$ to the south (Fig. 1). The main industries in Hout Bay harbour include tourism, recreational boating, and commercial fishing activities (including vessel repairs and fish processing factories), but there is limited international traffic. Hout Bay harbour was selected to pilot the $C$. maenas management as the harbour is much smaller than Table Bay and the European shore crab population in this harbour was thought to contain fewer individuals (Robinson, unpublished data 2013).

\subsection{Management plan}

A 2013 mark-recapture survey conducted in Hout Bay, estimated that there were 6,656 C. maenas individuals (95\% CI: 717-12,595) (Robinson, unpublished data 2013). Based on this, a management plan

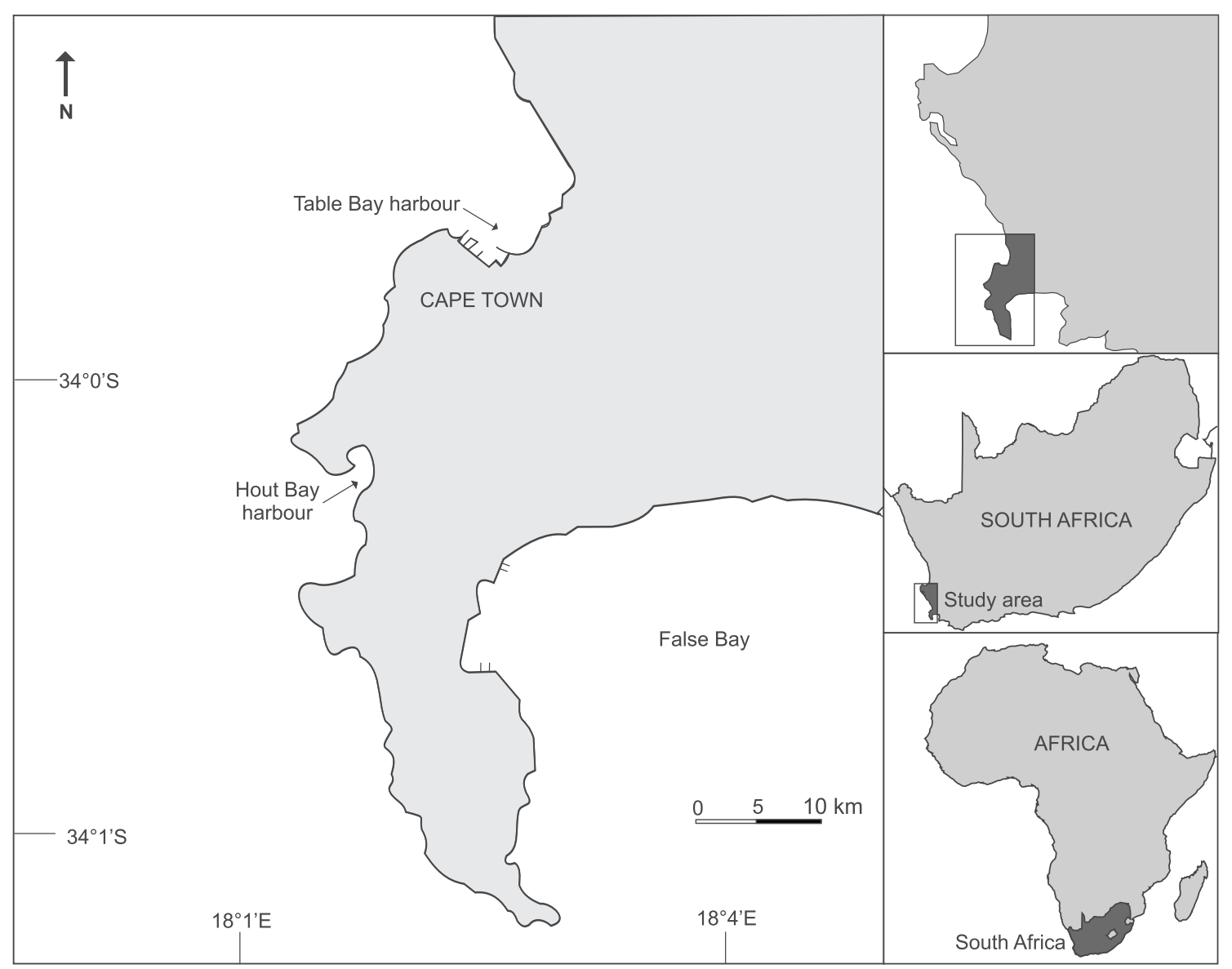

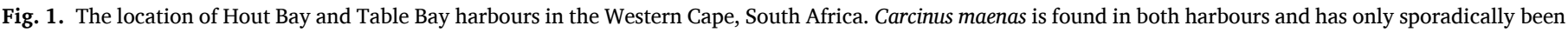
observed outside of these harbours (Mabin et al., 2017). The trial management was conducted in Hout Bay harbour. 
was developed consisting of three proposed phases. The first phase involved testing various removal methods used elsewhere (Anderson, 2005; De Rivera et al., 2007; Hewitt and McDonald, 2013). The second phase planned to deploy successful methods targeting both juvenile and adult crabs with the aim of significantly reducing the population. The goal was to reduce the catch per unit effort (CPUE) to $10 \%$ of the maximum CPUE recorded. In the third phase, the control measures of the second phase were to be supplemented with subtidal collections by scientific SCUBA divers to catch any remaining crabs. Four divers were to be deployed simultaneously to collect crabs following a $50 \mathrm{~m}$ line in a grid pattern. Management was to cease once no crabs were detected for 40 continuous days, i.e. the larval period for $C$. maenas (Mohamedeen and Hartnoll, 1989). Thereafter the population was to be monitored every two weeks for the following 12 months.

Best practice guidelines for the trapping and euthanasia of $C$. maenas were developed in conjunction with the Cape Invasive Alien Animal Working Group (Davies et al. in press). This group includes members from various academic institutions, employees from provincial government and local conservation departments, as well as representatives from the Society of Protection and Care of Animals (SPCA). The South African National Biodiversity Institute (SANBI) and Stellenbosch University have animal ethics policies regarding research animal euthanasia though neither deals with invertebrates. The most comprehensive source available was a set of guidelines from Australia \& New Zealand that explicitly considers various methods for euthanizing crabs (Reily, 2001). Some of the methods which are listed as recommended (e.g. clove oil baths or a fatal injection of Pentobarbitone) were not possible to implement at the scale expected in this study. Chilling followed by freezing is listed as 'acceptable with reservations' (Reily, 2001) and this is the standard method of euthanasia for invertebrates used currently in scientific research and the food industry in South Africa. Therefore, in this study, following removal from the harbour, crabs were placed in cool seawater until the end of the day, when they were euthanised via freezing. Death was confirmed when crabs ceased movement and the onset of rigor mortis was observed. Several specimens were donated to local universities for student dissections and school outreach programmes, reducing the need for the collection of native crab species for these purposes. All remaining crabs were incinerated as biological waste by the City of Cape Town Invasive Species Unit.

\subsection{Trial of methods}

Four methods for removing crabs were trialled and their efficacy was assessed so as to identify the most appropriate for management in the South African context (Fig. 2). Both baited traps and crab condos were considered because the former rely on the predatory nature of crabs, while the latter offer a source of shelter for juveniles which can be excluded from baited traps due to competition or cannibalism by larger individuals (Miller, 1978). Collection by divers was considered for targeting crabs not attracted to the traps (i.e. those uninterested in feeding, trap-shy, or occurring in areas that were out of the range of the traps or condos). It was anticipated that this would be particularly useful in the open areas of the harbour (with no surface platform) where trapping was logistically impossible due to the commercial nature of the harbour. Lastly, as C. maenas is known to bury into the benthic substrate (Behrens Yamada, 2001), sediment dredging offered an approach to target individuals that were not visible to the divers.

\subsubsection{Crab condos}

Crab condos (Fig. 2a) were used to target juveniles. Condos were soaked for each of $12 \mathrm{~h}$ during daylight, $12 \mathrm{~h}$ during darkness, $24 \mathrm{~h}$ and $48 \mathrm{~h}$ as well as two bait conditions (baited and unbaited), each with four replicates. Longer soaks were necessary for these traps as those without bait required adequate time to be encountered. In order to avoid the theft of traps, this method was trialled in a secure area of the harbour. Baited traps contained $75 \mathrm{~g}$ of chopped sardines wrapped in nylon material. The CPUE was examined with respect to bait condition (two levels: baited and unbaited) and soak duration (four levels: $12 \mathrm{~h}$ during daylight, $12 \mathrm{~h}$ during darkness, $24 \mathrm{~h}$ and $48 \mathrm{~h}$ ) in a two-factor generalised linear model (GLM), using a quassipoisson error distribution.

\subsubsection{Baited traps}

To establish the optimal deployment period, the CPUE of baited traps (Fig. 2b) was assessed under various soak durations in Hout Bay harbour. Three traps were deployed at three locations for each of one, two and $4 \mathrm{~h}$ (n 9 per soak duration). Carcinus maenas trapping programmes typically have longer (i.e. 18-24 h) soak times (De Rivera et al., 2007; Duncombe and Therriault, 2017). However, as traps were stolen even during daytime, the traps could not be left unattended and thus a shorter soak time was necessary. Traps were baited with $200 \mathrm{~g}$ of crushed sardines. Traps were placed at least $20 \mathrm{~m}$ apart, at a water depth of 6-8 $\mathrm{m}$. All trials were conducted during daylight hours in a soft-sediment benthic habitat. The CPUE was calculated as the number of crabs collected per trap per hour and this was $\log \left(\begin{array}{ll}x & 1\end{array}\right)$ transformed to analyse the effect of soak duration on CPUE. As with all statistics and population modelling in this study, the analysis was conducted in the $\mathrm{R}$ statistical environment ( $\mathrm{R}$ core team, 2016).

To assess the efficacy of the baited traps, crabs were collected from the Royal Cape Yacht Club in Table Bay harbour and put in a $3000 \ell$ circular tank (diameter $2.75 \mathrm{~m}$, height $0.75 \mathrm{~m}$ ) with water temperatures reflecting fluctuations in ambient temperature. Four densities of crabs (12, 24, 48 and 96 crabs per trial) were tested with three replicates of each density. After crabs had been allowed a minimum of $12 \mathrm{~h}$ to acclimatise, a baited trap was deployed in the centre of the tank. After 2 $\mathrm{h}$ (the optimal soak duration determined in the initial trials, see Results for further details), the number of crabs captured in the trap was recorded. The data were analysed using a one-factor GLM, with a binomial, poisson and quasipoisson error distribution to assess the effect of crab density on the proportion of crabs caught per soak.

\subsubsection{Diver collections}

In order to determine the efficacy of diver collections (Fig. 2c) as a potential management method, empty $C$. maenas carapaces were placed along a $50 \mathrm{~m}$ transect line, dorsal surface upwards. Carapaces were weighed down with $10 \mathrm{~g}$ weights attached to the ventral surface with epoxy putty. Each transect had a random combination of nine carapaces from each of the four size classes (small $40 \mathrm{~mm}$, medium 41-60 mm, large $61-80 \mathrm{~mm}$ and extra-large $81 \mathrm{~mm}$ ) placed randomly up to $1 \mathrm{~m}$ either side of the transect line. Three scientific SCUBA divers (who had successfully collected live $C$. maenas on previous dives and thus were familiar with the target species) conducted three transects each. Empty carapaces returned to the surface were recorded as "detected" and any remaining carapaces were considered "undetected". Efficacy of each dive was calculated as the proportion of detected carapaces returned by each diver relative to the total number of carapaces on the transect line.

\subsubsection{Sediment dredging}

The presence of $C$. maenas in the sediment in Hout Bay harbour was assessed by conducting five replicate transects with a sediment dredge (Fig. 2d). The dredge was towed along the seafloor by a boat at a constant speed of $0.28 \mathrm{~m} / \mathrm{s}$, and steered by a diver to ensure sediment collection to a maximum depth of $0.3 \mathrm{~m}$. Each transect was $0.58 \mathrm{~m}$ wide and $100 \mathrm{~m}$ long. Sediment was sieved through a $0.5 \mathrm{~cm}$ mesh layer at the base of the dredge and the remaining substrate was manually searched 
a)

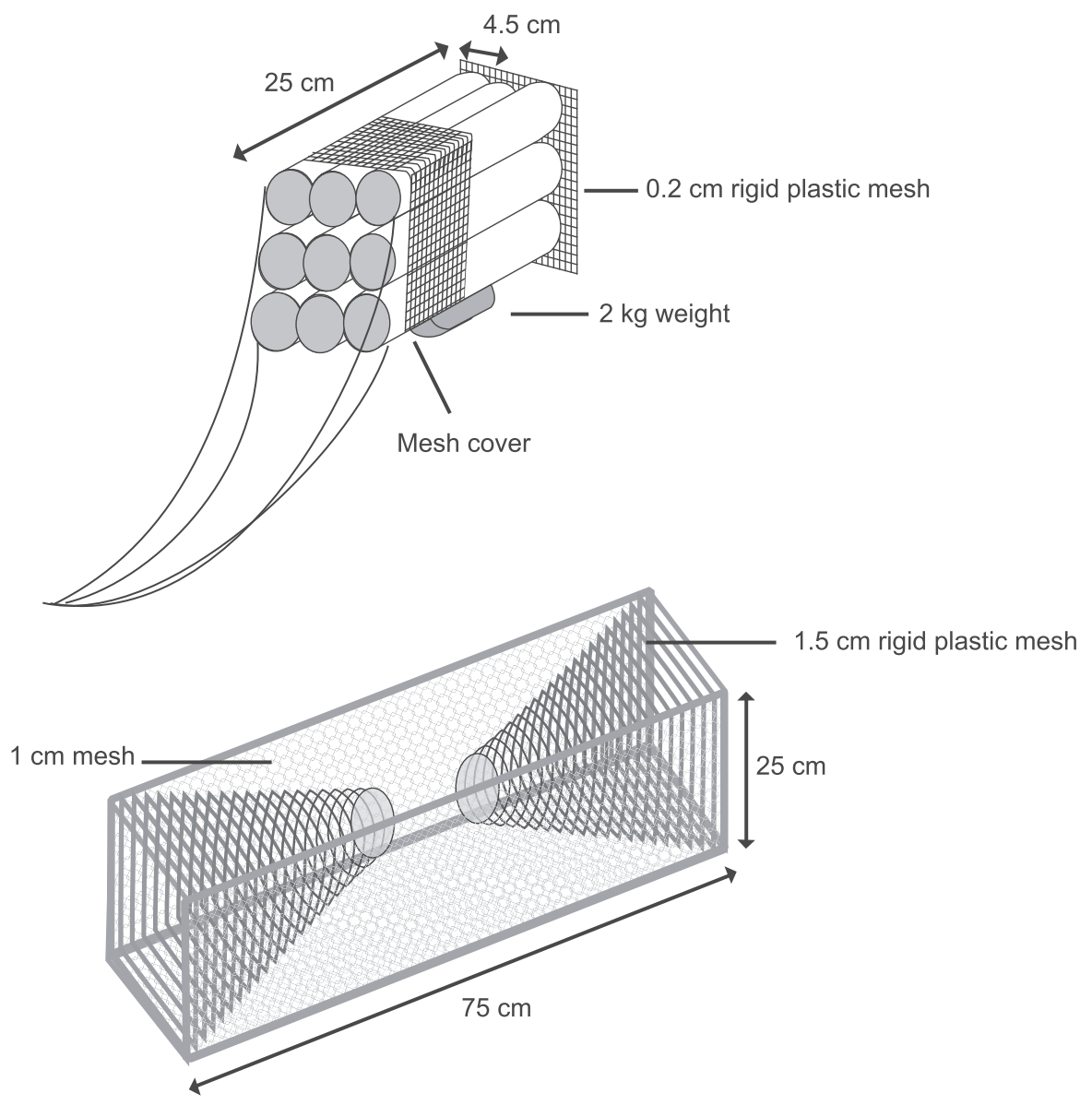

c)

d)
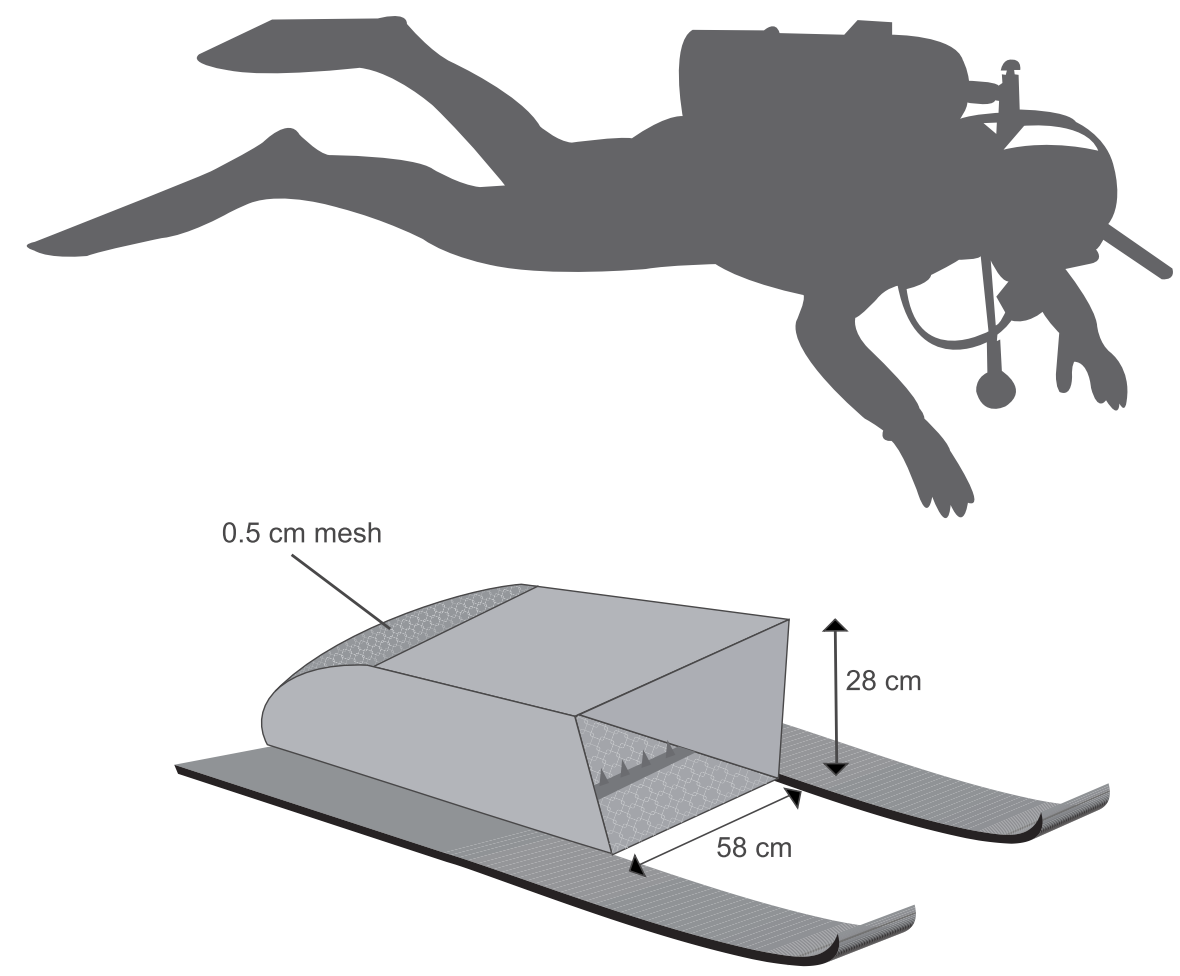

Fig. 2. Survey methods trialled to determine the suitability for crab collection in the South African context; a) Crab condo; b) Baited trap; c) Diver transects; and d) Sediment dredge. 
for C. maenas. Sex and carapace width was recorded for all individuals collected in the dredge. The number of crabs captured was examined with respect to sex (two levels: male and female) and size (four levels: small, medium, large and extra-large) using a two-factor GLM, with a quasipoisson error distribution.

\subsection{Management trial}

Management commenced in Hout Bay harbour on June 23, 2014 and continued until June 30, 2015 (219 trapping days). The team consisted of ten field assistants and one field manager who were employed on a full-time basis. A management hiatus of 1.5 months occurred in December 2014 and January 2015 due to administrative restrictions related to the reissuing of the collection permit by regulatory authorities and the appointment of a new field team.

A total of 100 traps were deployed across the harbour daily, for $2 \mathrm{~h}$ each. These were placed approximately $20 \mathrm{~m}$ apart. Each trap was baited with 150-200 g of defrosted, crushed sardines. Crabs that were caught were sexed and sized based on carapace width. At the end of the day, all crabs caught were euthanised via freezing and then incinerated as biological waste.

Following the termination of management, monitoring continued for six months (July to December 2015) with 40 baited traps deployed for 2 $\mathrm{h}$ each, once a month. Monitoring reflected $40 \%$ of the average daily effort recorded during the active management phase. The methodology employed was consistent with the removal methods used during active management, except all crabs caught were released at the end of each monitoring day, to ensure that the number captured the following month was not biased by their removal. Monitoring focused on the sites identified as the most productive. These sites were deemed optimal habitat for the crabs due to the disposal of fisheries discards which would provide an easy food source for the crabs.

The management and monitoring catch data were analysed separately as they represent different approaches. Data collected during the first six days of the management phase were excluded from all analyses as this period was considered a learning period for the field team. Catch per unit effort (defined as the number of crabs caught per 8-h day) was examined with respect to size (4 levels: small, medium, large and extralarge), month (12 levels for the management phase: July 2014-June 2015; 6 levels for the monitoring phase: July-December 2015) and sex (2 levels: male and female) using a three-factor GLM, with a quasipoisson error distribution. Pairwise t-tests with Bonferroni corrections were used on a post hoc basis. A one factor GLM with a binomial distribution was used to analyse the effect of month on the number of gravid and non-gravid females caught. Month was coded as a factor for all analyses.

\subsection{Administrative costs}

Reports of realised management costs for invasive species are often excluded from the scientific literature. However, this information is extremely useful for future management planning and also to analyse the total costs associated with invasive species. SANBI employed all personnel involved in the management programme on a contractual basis. Salaries ranged from 32.34 to 67.93 South African Rand (ZAR) per hour based on educational experience and government-defined pay rates. The bursary costs for the lead scientist during the 12 months of management was included in lieu of a salary. Equipment was purchased prior to management so represented a once-off cost (apart from the occasional replacement or repair cost). The bait used daily during the management and monitoring phases was a regular expenditure. Storage costs included the rental of the space in which the freezer was stored and electricity charges associated with this over the period of 18 months. Expenses were incurred in transporting the crabs to the disposal facility. Disposal fees (for the incineration of the euthanised crabs) were paid by the Biodiversity Management Branch of the City of Cape Town but are included in the total costs incurred. The costs involved in trialling the potential management methods are not included, neither are the costs of academic or administrative support. As such the costs presented represent an estimate of direct costs incurred during the management programme only.

\section{Results}

\subsection{Trial of methods}

\subsubsection{Baited traps}

There was no significant difference in CPUE between the various soak durations for baited traps ( $\mathrm{H} \quad 3.0, \mathrm{df} \quad 2, \mathrm{p} \quad 0.22$, Fig. 3.). It is, however, notable that the variance was significantly different $(\mathrm{F} \quad 0.03$, df $26, p<0.001$ ), declining with increasing soak time. As such, an intermediate soak duration of $2 \mathrm{~h}$ was selected for practical purposes i.e. the time taken to empty and redeploy the traps.

There was no relationship between crab density and the proportion of crabs caught when tested using a generalised linear model with binomial errors $\left(\mathrm{X}^{2}{ }_{1,11}, p \quad 0.22\right)$, even if only the two lowest crab densities were compared $\mathrm{X}_{\mathrm{df}}^{2}{ }_{1,6}, p \quad 0.13$ ), but there was also only a marginally statistically significant increase in the numbers of crabs caught with density $\left(\mathrm{F}_{1,11} \quad 4.6, p \quad 0.03\right.$ from a generalised linear model with poisson errors) that disappeared if overdispersion were accounted for by using a model with quasipoisson errors $\left(\mathrm{F}_{1,11} \quad 4.6, p\right.$

0.16 , dispersion $\sim 2$ ). This suggests that the baited traps would successfully target Carcinus maenas even at low densities towards the end of management. As such these were deemed an appropriate method for catching the crabs.

\subsubsection{Crab condos}

No C. maenas or native crab species were caught in Hout Bay harbour

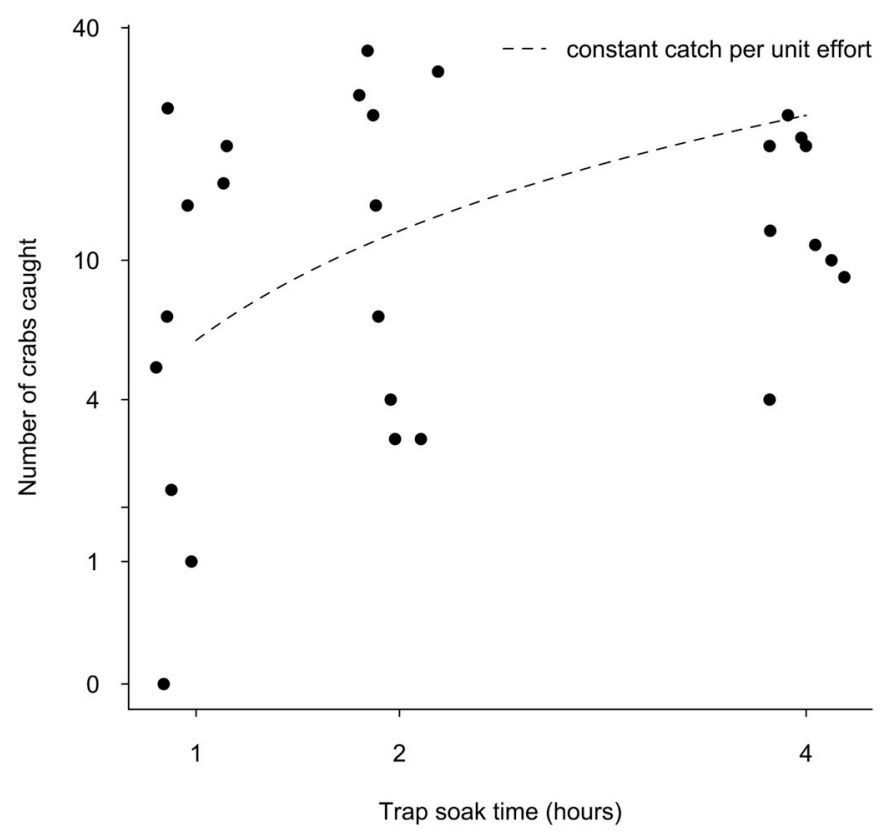

Fig. 3. The effect of trap soak time on the number of crabs caught. There was no effect of trap soak time on the log (numbers of crabs caught 1 ), F 2.2, df $26, p \quad 0.15$. The line shown assumes the CPUE remains constant over time and is extrapolated from the numbers of crabs caught after $1 \mathrm{~h}$. This line suggests that the catch per unit effort declines between two and $4 \mathrm{~h}$ soak time, although this effect was not statistically significant. Note some jitter is added to the $\mathrm{x}$-values to avoid over-plotting. 
during the $768 \mathrm{~h}$ of crab condo deployment. The sardines in the baited condos remained untouched at the end of the soak.

\subsubsection{Diver collection}

Divers recovered a total of 55 crab carapaces out of 100 placed along a transect line during the efficacy survey, with a median efficacy per diver of 56\% (ranging from 27 to $83 \%$ ). In reality, the live crabs would be mobile, making them easier to detect if they were to move across the diver's line of sight. However, due to the low efficacy of this method, diver removal is not seen as a long-term management option in South Africa, particularly not for reducing large populations.

\subsubsection{Sediment dredging}

No life-history stages of $C$. maenas were present in the dredged substrate collected in Hout Bay harbour. Other macrofaunal species were retained within the dredge, but this did not include any native crabs.

\subsection{Management trial}

\subsubsection{Management and monitoring results}

Over a period of 12 months and a total of 219 trapping days, 36,244 C. maenas were collected in Hout Bay harbour (Fig. 4.). On the 16th day of trapping, the maximum daily catch was recorded (1,079 crabs), while the lowest daily catch (13 crabs) occurred 361 days after management initiation.

During the monitoring phase, which followed active management, the daily catches increased, peaking five months after management was terminated when a total of $120 \mathrm{C}$. maenas were collected. Unexpectedly, the crab catches decreased in the last month of monitoring (there was no planned reduction in effort).

Size, sex and month (and the interactions between these main effects) all significantly affected CPUE (Table S1). CPUE was significantly different between all size classes (pairwise comparisons; $p<0.001$ ) except for the small and extra-large crabs which both had low CPUE ( $p$

0.76). In the first few months of active management, the highest CPUE

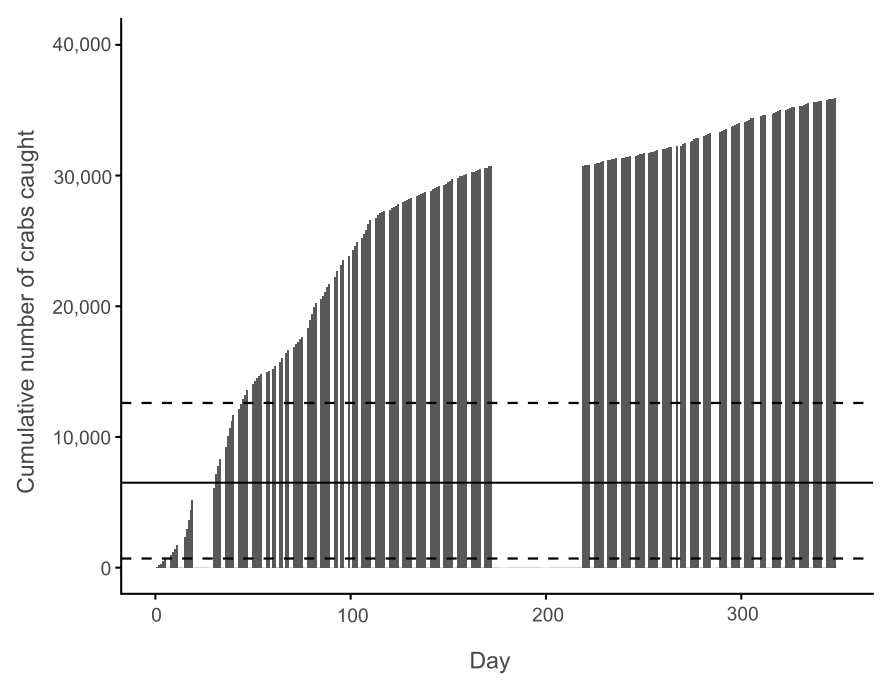

Fig. 4. Cumulative number of crabs caught during the trial management in Hout Bay Harbour. Day 1 was the June 23, 2014 and Day 219 the June 30, 2015. Gaps in the graph indicate non-trapping days such as weekends and a 46day hiatus over December and January (due to administrative issues). The horizontal lines represent the previous population estimates (Robinson, unpublished data 2013): lower dashed line (lower 95\% confidence interval); solid line (population estimate of 6656) and upper dashed line (upper 95\% confidence interval). recorded was that of large crabs (Fig. S1). However, the highest CPUE recorded towards the end of the management phase was that of medium (41-60 mm) crabs. The CPUE of males and females was significantly different $(p<0.001)$, with more females collected than males during the first half of the active management phase (Table S1). However, the sex ratio of females to males caught per day reached 1:1 as management action continued (Fig. S2). CPUE declined significantly among months from July to November $2014(p<0.001)$, and thereafter remained at low levels.

During the monitoring phase, the effects of size, sex and month on CPUE were significant, as were all interactions, except the three-way interaction (Table S2, Fig. S1). CPUE was lowest for extra-large and small crabs with no significant difference between these size groups ( $p$ 1.0) while catches of medium and large crabs were higher $(p \quad 1.0)$. The CPUE of males was significantly higher than females ( $p \quad 0.027)$. The CPUE recorded in November, the second last month of monitoring, was significantly higher than all other months $(p<0.001)$, except for October ( $p$ 0.076). Of the total females captured during monitoring, 1,158 were gravid. Gravid females were found in every month of the year with no significant effect of month on the abundance collected $\left(\mathrm{X}^{2}\right.$ 288, df 272, $p \quad$ 0.242) (Fig. 5).

The original plan for the management of $C$. maenas in South Africa was to introduce divers for collections once the catches had dropped below $10 \%$ of the maximum CPUE or daily catch recorded. In this case, the maximum CPUE was achieved on day 14, when 7.7 crabs were caught per hour of trapping. On day 33, 0.8 crabs were caught per hour. However, once the dive team was assembled over the following two weeks, the CPUE had increased again to $40-50 \%$ of the maximum. This increase was most likely caused by fluctuations in catches. At this point, it was decided that the $10 \%$ maximum CPUE should be sustained for 20 trapping days prior to diver introduction. The first time that this was achieved was on the 133rd day of trapping (following the management hiatus from December 2014 to January 2015). However, this coincided with a renewal of work contracts for the field team, therefore the trapping programme was continued for a further six months. In addition, the costs of hiring a dive team for crab collections were then considered prohibitively high (approximately ZAR 6,000 per day). After careful consideration of these issues, a decision was made to concentrate solely on trapping for the remainder of the programme.

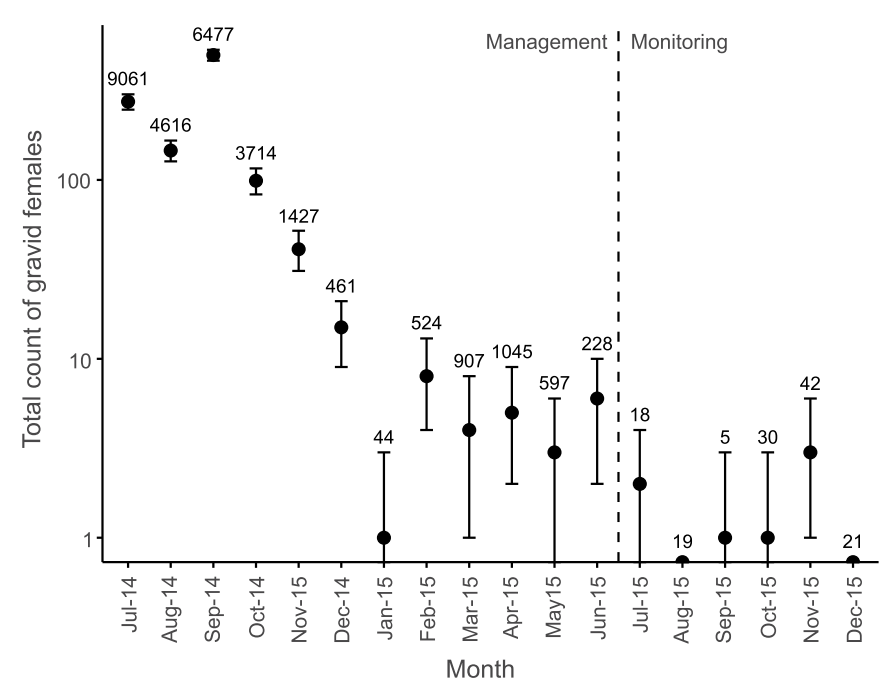

Fig. 5. Patterns in the abundance of gravid and non-gravid female crabs captured during management and monitoring in Hout Bay harbour. The total counts of gravid females per month are summed for each month and displayed with $95 \%$ confidence intervals. The total number of non-gravid females is displayed above each point. Gravid females were caught in every month. 
Table 1

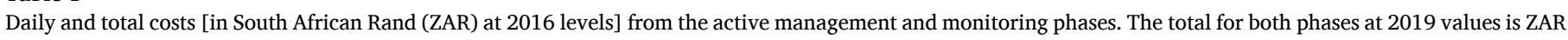
$1,033,333$.

\begin{tabular}{|c|c|c|c|c|c|}
\hline Category & Management daily & Management total & Monitoring daily & Monitoring total & Grand total \\
\hline Salaries (research assistants) & 3,278 & 734,250 & 392 & 2,350 & 736,600 \\
\hline Salary (Lead scientist) & 274 & 100,000 & 0 & 0 & 100,000 \\
\hline Equipment & 32 & 7,201 & 0 & 0 & 7,201 \\
\hline Storage & 37 & 8,269 & 530 & 3,181 & 11,450 \\
\hline Transport & 7 & 1,566 & 65 & 393 & 1,958 \\
\hline Bait & 52 & 11,612 & 17 & 102 & 12,559 \\
\hline Disposal & 50 & 11,194 & 0 & 0 & 11,194 \\
\hline Total & ZAR 3,730 & ZAR 874,092 & ZAR 1,004 & ZAR 6,025 & ZAR 884,632 \\
\hline
\end{tabular}

\subsubsection{Administrative costs}

The greatest cost of the management phase was for the payment of salaries, with this amounting to $\sim$ ZAR 835,000 (Table 1 ). The total person hours worked during the active management period was 18,450 h. Over the 218 trapping days, the mean daily expenditure on salaries was ZAR 3,552. Personnel costs were much lower during the monitoring phase, amounting to a total of ZAR 2,350 for the six days of work. As the co-ordinator of this programme was financially supported by an educational bursary, a salary for a lead scientist is expected to be higher than the costs incurred in this project.

\section{Discussion}

Invasive species management programmes must continuously reassess priorities to determine whether management actions should continue or whether resources might be better spent on improving detection rates or ecological restoration. If time permits, pilot management programmes can assist in informed decision-making through the collection and analysis of quantitative and qualitative data prior to committing to a long-term programme. In this case study, a decision was made to cease management after 12 months on several grounds: 1 ) the initially budgeted funds were depleted; 2) the population was much larger than previously estimated and thus management would be necessary for longer than planned; 3 ) initial studies suggested that the ecological impact of this species in the harbour environment was minimal (Mabin unpublished data); and 4) the potential for recolonisation was unquantified, although a potential for continued immigration of crabs into Hout Bay harbour was recognised. Although extirpation was not achieved, valuable insights have been gained that can be considered during future management programmes. The decision-making process is illustrated in Fig. 6.

Eradication feasibility can be assessed by taking into account the following aspects of an invasion: (1) the biology of the target species; (2) the physical and social characteristics of the invasion site; and (3) implementation of suitable control methods (Anderson, 2005). Application of this framework to the Carcinus maenas invasion in South Africa highlights several gaps in scientific knowledge and institutional capacity. For example, although the biology of the target species is fairly well known from studies conducted elsewhere, both in its native and invasive range (see Behrens Yamada, 2001 for a review), attributes such as the timing and rate of reproduction which are often context specific, were unknown at the outset of this management programme. Invasive species management programmes should target all individuals, including juveniles as well as adults of reproductive size [C. maenas is capable of reproducing from a carapace width of $27 \mathrm{~mm}$ (Mohamedeen and Hartnoll, 1989)]. Ideally, management action should occur prior to the breeding season (Genovesi, 2007; Panetta, 2007; Pardini et al., 2008; Wilson et al., 2017), however, in South Africa, C. maenas breeds throughout the year (Mabin et al., 2017) so there was no ideal time to initiate management. In addition, juvenile crabs were not targeted and this likely reduced the probability of extirpation.

In this study, the social and physical contexts of the site determined the management methods selected. High opportunistic crime rates around Hout Bay harbour meant that traps were often stolen even during daylight hours. While the international practice is to soak C. maenas baited traps for approximately $24 \mathrm{~h}$ (De Rivera et al., 2007; Duncombe and Therriault, 2017), this approach was impractical in this case. As such, in an effort to balance the logistical challenges associated with short trap deployments while maximising catches, a management decision was made to employ a 2-h soak period for this study. Crab condos have been used successfully in Australia to capture small C. maenas (Hewitt and McDonald, 2013), as well as in Table Bay (Mabin et al., 2017). However, the condos were unsuccessful at capturing the crab in Hout Bay. It is most likely that the low catch rates reflect their deployment in an area that was later identified as supporting low densities of C. maenas. This was unavoidable as it was the only secure area in the harbour in which traps could be deployed with minimal theft risk for the longer soak periods they required.

Marine invasive species have previously been targeted using volunteer divers [e.g. the collection of lionfish in the Caribbean (Frazer et al., 2012) and zebra mussels in the USA (Wimbush et al., 2009)]. However, in South Africa, all biological sampling is classified as non-recreational diving and therefore, legally, all scientific divers need to be commercially certified, working in a minimum team of four people with monetary reimbursement for their time (Occupational Health and Safety Act 2002). This has important financial implications for management authorities as the cost of employing a commercial dive team would be prohibitive and therefore is not a long-term management option. It might, however, be appropriate in areas inaccessible to traps, where the aim is to remove the last few individuals, or as a check before declaring eradication complete.

The collection of crabs by sediment dredging was unsuccessful in this study. As the dredge was pulled behind a boat, only open areas of the harbour could be accessed. The fact that $C$. maenas commonly avoids exposed sandy areas (Hedvall et al., 1998; Moksnes et al., 1998) likely explains the absence of crabs in dredged sediments. Therefore, although this method of collection is not appropriate for this species, it might have more applicability to invasive species that are solely sediment dwelling, such as aquatic plants or clams (Eichler et al., 1993).

While only baited traps were successfully used in Hout Bay, minor modifications to the design of these traps might further improve CPUE rates. In Canada, the most common baited trap design captured only $16 \%$ of $C$. maenas individuals that attempted to enter the trap (Bergshoeff et al., 2018). The CPUE was increased by $81 \%$ through simple design modifications (Bergshoeff et al., 2019). If a future attempt was made to eradicate the crabs from elsewhere, a mix of capture strategies would be recommended. The utilisation of a combination of methods has previously been highlighted as the most appropriate approach to management (Courchamp and Sugihara, 1999; An et al., 2007). This study has indicated that it would be best for future Carcinus management programmes to use baited traps on a daily basis with divers employed strategically, and crab condos used where they are found to be effective.

In addition to the factors considered by Anderson (2005), this study highlighted the importance of project administration and continuity. Sufficient financial support is key to successful invasive species management (Myers et al., 2000) although it is often challenging to secure 


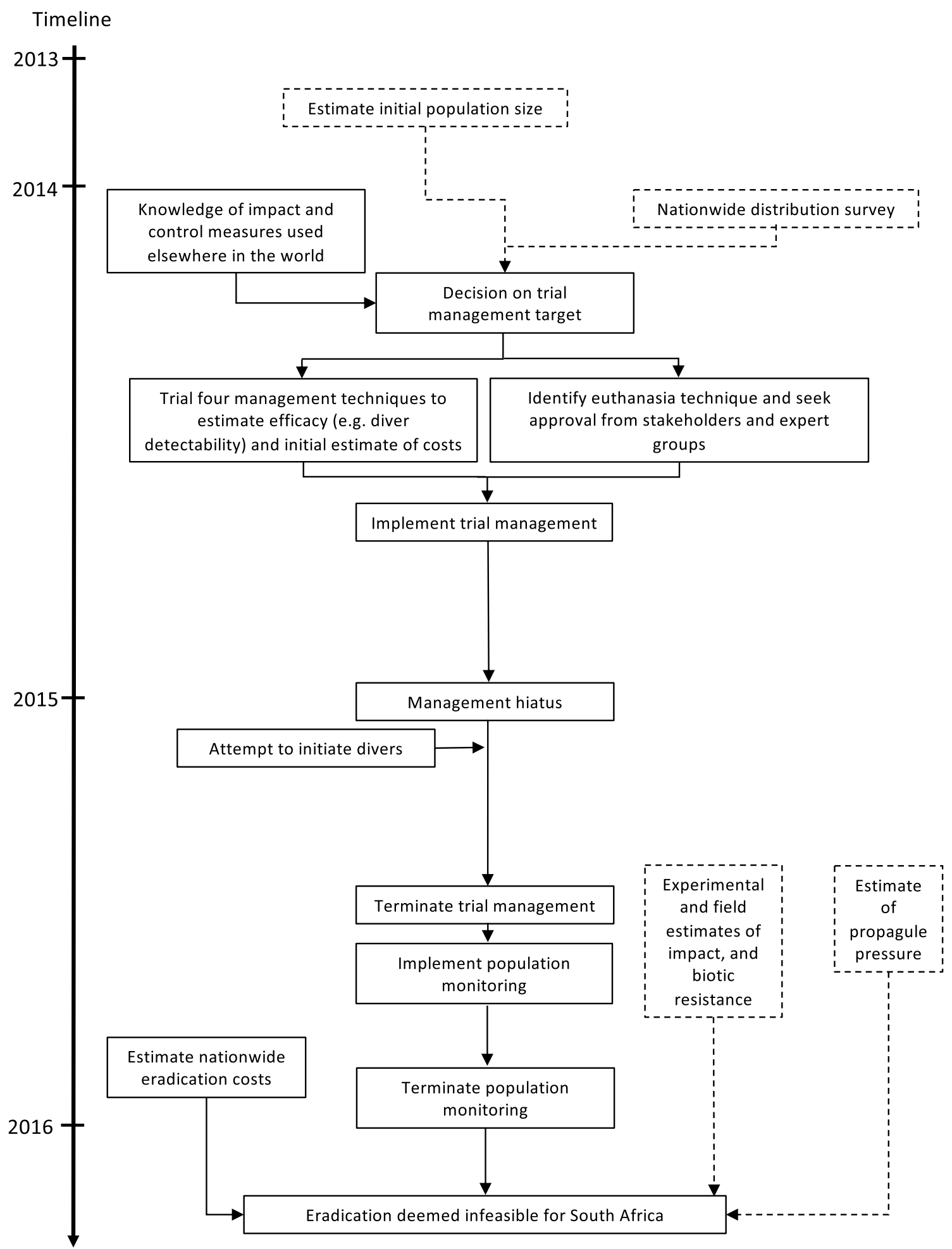

Fig. 6. Key steps made during the management trial of Carcinus maenas in South Africa. This process led to the ultimate decision that eradication of the crab was infeasible given the current distribution, and not a priority given the apparently low threat. Dotted lines indicate processes that are not explicitly part of this paper, but part of the overall decision-making process.

funds, especially when these are linked to predefined financial periods and political objectives. Given that extirpation was unsuccessful, it is likely that successful management would require considerably more effort and thus the associated costs would be higher. Such costs should also be considered in the context of a national eradication programme, e. g. if Table Bay harbour were targeted as well, then costs would increase. Volunteers or citizen scientists are often utilised for conservation work in developed countries (Scyphers et al., 2015) and such programmes have been undertaken to monitor terrestrial systems in South Africa (Barnard et al., 2017). Citizen scientists were used successfully for monitoring C. maenas in the USA (Delaney et al., 2008). Based on the experience gained in this project, it is suggested for future management that personnel be employed where costs and circumstances allow and then volunteers be used to assist with any gaps in staffing. Ideally, 
employment contracts should be linked to the proposed duration where possible. If an invasion requires a rapid response, confirmation of contracts could be challenging to organise at short notice, but every effort should be made to do so. In South Africa, anybody employed for more than three months is automatically considered permanent staff (Basic Conditions of Employment Amendment Act, 2002). If the duration of management programmes is increased, legally, temporary staff must be made permanent. This then has financial implications for the management authority as permanent employees are entitled to benefits. If it is necessary to maintain short contracts for these legal reasons, there must be an adequate hand-over period to ensure that skills are not 'lost' when new staff are employed. In addition to employment contracts, similar problems can arise with the issuing of research permits. In South Africa, in order to conduct any biological research or management, the government must issue a permit for such work. The current research permit system is very rigid: permits are issued for a maximum of twelve months and expire at the end of the calendar year. If permits could reflect the proposed project duration, this would reduce the risk of any unnecessary delays as well as reducing the administrative workload.

\section{Conclusion}

Most of the successful marine eradication programmes to date have targeted newly detected species (Anderson, 2005; Bax et al., 2002; Wotton et al., 2004; Miller et al., 2004; Hopkins et al., 2011), with one exception where a locally established pest was discovered at an aquaculture facility and the intertidal surrounding area (Culver and Kuris, 2000). If the target species is well established, such as Carcinus maenas in South Africa, there is usually no time pressure to initiate management immediately. Therefore, the most effective control methods can be trialled in the local context. This provides a strong basis for scientifically informed management decisions. In contrast, if a species is recently detected, time is usually limited and thus management relies on methods tried and tested elsewhere. These might not be as effective in a different context, therefore adequate monitoring will be crucial in such situations to ensure control efforts are adaptive. Eradication might still be possible without this targeted methodology, but management goals are likely to take longer to achieve.

\section{Declaration of competing interest}

None.

\section{CRediT authorship contribution statement}

Clova A. Mabin: Conceptualization, Investigation, Writing - original draft. John R.U. Wilson: Conceptualization, Writing - review \& editing. Johannes J. Le Roux: Resources, Writing - review \& editing. Prideel Majiedt: Resources, Writing - review \& editing. Tamara B. Robinson: Conceptualization, Investigation, Resources, Writing - review \& editing, Supervision.

\section{Acknowledgements}

This study was made possible by funding from the then South African Department of Environment Affairs through the South African National Biodiversity Institute (SANBI) Marine Programme. Note that this publication does not necessarily represent the views or opinions of the government department or its employees. CM acknowledges the DSINRF Centre of Excellence for Invasion Biology for bursary support. Many people were involved in the massive undertaking to remove the crab population from Hout Bay harbour. The team at SANBI (Dr Kerry Sink, Siyansanga Miza and Phillip Ivey) are thanked for logistical support and the field managers (Dr Shannon Hampton, Hannah Raven and Nicolas Djikerman) and the many research assistants are acknowledged for their many hours in the field. The CAPE Invasive Alien Animal
Working Group (CAPE IAAWG) provided useful advice and support. An anonymous reviewer is thanked for their insightful comments that helped to strengthen this paper.

\section{Appendix A. Supplementary data}

Supplementary data to this article can be found online at https://doi. org/10.1016/j.jenvman.2020.110213.

\section{References}

An, S.Q., Gu, B.H., Zhou, C.F., Wang, Z.S., Deng, Z.F., Zhi, Y.B., Li, H.L., Chen, L., Yu, D. H., Liu, Y.H., 2007. Spartina invasion in China: implications for invasive species management and future research. Weed Res. 47, 183-191.

Anderson, L.W., 2005. California's reaction to Caulerpa taxifolia: a model for invasive species rapid response. Biol. Invasions 7, 1003-1016.

Barnard, P., Altwegg, R., Ebrahim, I., Underhill, L.G., 2017. Early warning systems for biodiversity in southern Africa - how much can citizen science mitigate imperfect data? Biol. Conserv. 208, 183-188.

Basic Conditions of Employment Amendment Act, 2002.

Bax, N., Hayes, K., Marshall, A., Parry, D., Thresher, R., 2002. Man-made marinas as sheltered islands for alien marine organisms: establishment and eradication of an alien invasive marine species. In: Veitch, C.R., Clout, M.N. (Eds.), Turning the Tide: the Eradication of Invasive Species. IUCN SSC Invasive Species Specialist Group. IUCN [World Conservation Union], Gland, Switzerland, and Cambridge, UK, pp. 26-39.

Behrens Yamada, S., 2001. Global Invader: the European Green Crab. Oregon Sea Grant. Oregon State University, p. 123.

Bergshoeff, J.A., McKenzie, C.H., Best, K., Zargarpour, N., Favaro, B., 2018. Using underwater video to evaluate the performance of the Fukui trap as a mitigation tool for the invasive European green crab (Carcinus maenas) in Newfoundland, Canada. PeerJ 6, e4223.

Bergshoeff, J.A., McKenzie, C.H., Favaro, B., 2019. Improving the efficiency of the Fukui trap as a capture tool for the invasive European green crab (Carcinus maenas) in Newfoundland, Canada. PeerJ 7, e6308.

Broekhuysen, G.J., 1936. On development, growth and distribution of Carcinides maenas. Arch. Neerl. Zool. 2, 257-399.

Carlton, J.T., Cohen, A.N., 2003. Episodic global dispersal in shallow water marine organisms: the case history of the European shore crabs Carcinus maenas and C. aestuarii. J. Biogeogr. 30, 1809-1820.

Chades, I., Martin, T.G., Nicol, S., Burgman, M.A., Possingham, H.P., Buckley, Y.M., 2011. General rules for managing and surveying networks of pests, diseases, and endangered species. Proc. Natl. Acad. Sci. Unit. States Am. 108, 8323-8328.

Courchamp, F., Sugihara, G., 1999. Biological control of alien predator populations to protect native island prey species from extinction. Ecol. Appl. 9, 112-123.

Culver, C.S., Kuris, A.M., 2000. The apparent eradication of a locally established introduced marine pest. Biol. Invasions 2, 245-253.

Davies, S.J., Jordaan, M., Karsten, M., Terblanche, J.S., Measey, J., Turner, A., van Wilgen, N.J., Veldtman, R., Zengeya, T.A., 2020. In: van Wilgen, B.W., Measey, J., Richardson, D.M., Wilson, J.R., Zengeya, T.A. (Eds.), Experience and Lessons from Invasive and Alien Animal Control Projects Carried Out in South Africa. Biological Invasions in South Africa. Springer, Berlin (in press).

De Rivera, C.E., Grosholz, E.D., Ruiz, G.M., Larson, A.A., Kordas, R.L., Sytsma, M.D., 2007. Green crab management: reduction of an invasive population. In: Proceedings of Coastal Zone 07 Portland, Oregon July 22 to 26, 2007.

Delaney, D.G., Sperling, C.D., Adams, C.S., Leung, B., 2008. Marine invasive species: validation of citizen science and implications for national monitoring networks. Biol. Invasions 10, 117-128.

Duncombe, L.G., Therriault, T.W., 2017. Evaluating trapping as a method to control the European green crab, Carcinus maenas, population at Pipestem Inlet, British Columbia. Man. Biol. Invasions 8, 235-246.

Eichler, L.W., Bombard, R.T., Sutherland, J.W., Boylen, C.W., 1993. Suction harvesting of Eurasian watermilfoil and its effect on native plant communities. J. Aquat. Plant Manag. 31, 144-147.

Frazer, T.K., Jacoby, C.A., Edwards, M.A., Barry, S.C., Manfrino, C.M., 2012. Coping with the Lionfish invasion: can targeted removals yield beneficial effects? Rev. Fish. Sci. 20, 185-191.

Genovesi, P., 2007. Limits and potentialities of eradication as a tool for addressing biological invasions. In: Nentwig, W. (Ed.), Biological Invasions, Ecological Studies 193. Springer, pp. 385-400.

Grosholz, E.D., Ruiz, G.M., Dean, C.A., Shirley, K.A., Maron, J.L., Connors, P.G., 2000. The impacts of nonindigenous marine predator in California bay. Ecology 81, 1206-1224.

Hanks, R.W., 1961. Chemical control of the green crab, Carcinus maenas (L.). Proc. Natl. Shellfish. Assoc. 52, 75-86.

Hedvall, O., Moksnes, P.O., Pihl, L., 1998. Active habitat selection by megalopae and juvenile shore crabs Carcinus maenas: a laboratory study in an annular flume. Hydrobiologia 375, 89-100.

Hewitt, M.J., McDonald, J.I., 2013. The efficacy of crab condos in capturing small crab species and their use in invasive marine species monitoring. Manag. Biol. Invasion 4, 149-153. 
Hopkins, G.A., Forrest, B.M., Jiang, W., Gardner, J.P.A., 2011. Successful eradication of a non-indigenous marine bivalve from a subtidal soft-sediment environment. J. Appl. Ecol. 48, 424-431.

Joska, M.A., Branch, G.M., 1986. The European shore crab - another invader? Afr. Wildl. 40, 63-64.

Mabin, C.A., Wilson, J.R.U., Le Roux, J.J., Robinson, T.B., 2017. Reassessing the invasion of South African waters by the European shore-crab Carcinus maenas. Afr. J. Mar. Sci. 39, 259-267.

Matheson, K., McKenzie, C.H., Gregory, R.S., Robichaud, D.A., Bradbury, I.R., Snelgrove, P.V., Rose, G.A., 2016. Linking eelgrass decline and impacts on associated fish communities to European green crab Carcinus maenas invasion. Mar. Ecol. Prog. Ser. 548, 31-45.

Miller, R.J., 1978. Entry of Cancer productus to baited traps. ICES J. Mar. Sci. 38, 220-225.

Miller, A.W., Chang, A.L., Cosentino-Manning, N., Ruiz, G.M., 2004. A new record and eradication of the northern Atlantic alga Ascophyllum nodosum (Phaeophyceae) from San Francisco Bay, California, USA. J. Phycol. 40, 1028-1031.

Mohamedeen, H., Hartnoll, R.G., 1989. Larval and post-larval growth of individually reared specimens of the common shore crab Carcinus maenas (L.). J. Exp. Mar. Biol. Ecol. 134, 1-24.

Moksnes, P.O., Pihl, L., van Montfrans, J., 1998. Predation on postlarvae and juveniles of the shore crab Carcinus maenas: importance of shelter, size and cannibalism. Mar. Ecol. Prog. Ser. 166, 211-225.

Murphy, N.E., Goggin, C.L., 2000. Genetic discrimination of sacculinid parasites (Cirripedia, Rhizocephala): implication for control of introduced green crabs (Carcinus maenas). J. Crustac Biol. 20, 153-157.

Myers, J.H., Simberloff, D., Kuris, A.M., Carey, J.R., 2000. Eradication revisited: dealing with exotic species. Trends Ecol. Evol. 15, 316-320.

Occupational Health and Safety Act, 2002.

Ojaveer, H., Galil, B.S., Carlton, J.T., Alleway, H., Goulletquer, P., Lehtiniemi, M., Marchini, A., Miller, W., Occhipinti-Ambrogi, A., Peharda, M., Ruiz, G.M., Williams, S.L., Zaiko, A., 2018. Historical baselines in marine bioinvasions: implications for policy and management. PloS One 13, e0202383.

Panetta, F.D., 2007. Evaluation of weed eradication programs: containment and extirpation. Divers. Distrib. 13, 33-41.

Panetta, F.D., 2009. Weed eradication—an economic perspective. Invasive Plant Sci. Manag. 2, 360-368.

Panetta, F.D., 2015. Weed eradication feasibility: lessons of the 21st century. Weed Res. 55, 226-238.

Panetta, F.D., Csurhes, S., Markula, A., Hannan-Jones, M., 2011. Predicting the cost of eradication for 41 Class 1 declared weeds in Queensland. Plant Protect. Q. 26, $42-46$.
Pardini, E.A., Teller, B.J., Knight, T.M., 2008. Consequences of density dependence for management of a stage-structured invasive plant (Alliaria petiolata). Am. Midl. Nat. $160,310-322$.

Pluess, T., Jarosik, V., Pysek, P., Cannon, R., Pergl, J., Breukers, A., Bacher, S., 2012. Which factors affect the success or failure of eradication campaigns against alien species? PloS One 7, e48157.

R core team, 2016. R: A Language and Environment for Statistical Computing. R Foundation for Statistical Computing, Vienna, Austria. https://www.R-project.org/.

Reily, J.S., 2001. Euthanasia of animals used for scientific purposes. In: Produced by the Australian and New Zealand Council for the Care of Animals in Research and Teaching. Department of Environmental Biology, Adelaide University, p. 136.

Scyphers, S.B., Powers, S.P., Akins, J.L., Drymon, J.M., Martin, C.W., Schobernd, Z.H., Schofield, P.J., Shipp, R.L., Switzer, T.S., 2015. The role of citizens in detecting and responding to a rapid marine invasion. Conserv. Lett. 8, 242-250.

Shea, K., Kelly, D., Sheppard, A.W., Woodburn, T.L., 2005. Context-dependent biological control of an invasive thistle. Ecology 86, 3174-3181.

Taylor, C.M., Hastings, A., 2004. Finding optimal control strategies for invasive species: a density-structured model for Spartina alterniflora. J. Appl. Ecol. 41, 1049-1057.

Thresher, R.E., 1997. Proceedings of the First International Workshop on the Demography, Impacts and Management of Introduced Populations of the European Crab, Carcinus maenas. Centre for Research on Introduced Marine Pests Technical report 11 .

Turner, B.C., de Rivera, C.E., Grosholz, E.D., Ruiz, G.M., 2016. Assessing population increase as a possible outcome to management of invasive species. Biol. Invasions 18, 533-548.

van Wilgen, B.W., Wilson, J.R., 2018. The Status of Biological Invasions and Their Management in South Africa in 2017. South African National Biodiversity Institute, Kirstenbosch and DST-NRF Centre of Excellence for Invasion Biology, Stellenbosch, p. 398.

Williams, B.G., 1967. Laboratory rearing of the larval stages of Carcinus maenas (L.) [Crustacea: Decapoda]. J. Nat. Hist. 2, 121-126.

Wilson, J.R.U., Ivey, P., Manyama, P., Nanni, I., 2013. A new national unit for invasive species detection, assessment and eradication planning. South Afr. J. Sci. 109, 1-13.

Wilson, J.R., Panetta, F.D., Lindgren, C., 2017. Detecting and Responding to Alien Plant Incursions. Cambridge University Press, p. 286.

Wimbush, J., Frischer, M.E., Zarzynski, J.W., Nierzwicki-Bauer, S.A., 2009. Eradication of colonizing populations of zebra mussels (Dreissena polymorpha) by early detection and SCUBA removal: lake George, NY. Aquat. Conserv. 19, 703-713.

Wotton, D.M., O'Brien, C., Stuart, M.D., Fergus, D.J., 2004. Eradication success down under: heat treatment of a sunken trawler to kill the invasive seaweed Undaria pinnatifida. Mar. Pollut. Bull. 49, 844-849. 